Kong. Res. J. 4(2): 89-94, 2017

ISSN 2349-2694

Kongunadu Arts and Science College, Coimbatore.

\title{
RESILIENCE OF FERNS: WITH REFERENCE TO DESICCATION AND REHYDRATION STRESS OFFER NEW INSIGHTS
}

\author{
Kavitha, C.H., Meenu Krishnan and K. Murugan* \\ Plant Biochemistry and Molecular Biology Laboratory, \\ Department of Botany, University College, Trivandrum, 695 034, Kerala, India. \\ *E.mail: harimurukan@gmail.com
}

\begin{abstract}
Ferns are one of the oldest vascular plants in existence and they are the second most diverse group of vascular plants followed to angiosperms. To unravel fern success has focused on the eco-physiological power and stress tolerance of their sporophyte and the gametophyte generations. In this context, those insights encompass plant water relations, as well as the tolerance to and recovery from drought or desiccation stresses in the fern life cycle are reviewed. Lack of secondary xylem in ferns is compensated by selection for efficient primary xylem composed of large, closely arranged tracheids with permeable pit membranes. Protection from drought-induced hydraulic failure appears to arise from a combination of pit membrane traits and the arrangement of vascular bundles. Features such as tracheid-based xylem and variously sized megaphylls are shared between ferns and more derived lineages, and offer an opportunity to compare convergent and divergent hydraulic strategies critical to the success of xylem-bearing plants. Similarly the synthesis and accumulation of sugar, proline and stress proteins along with the production of pool of polyphenols add strength to desiccation stress. Thus, it can possible to suggest that selection acted on the physiology in a synchronous manner that is consistent with selection for drought tolerance in the epiphytic niche, and the increasingly diverse habitats of the mid to late Cenozoic.
\end{abstract}

Keywords: Ferns, desiccation, rehydration stress, osmolytes, vasculature, polyphenols.

\section{INTRODUCTION}

Phylogenetic analysis reveals that land plants evolved from simple aquatic algal progenitors (Bennici, 2008). The radiation of once aquatic species on to dry terrestrial habitat required the evolution of adaptive features suites that permitted life in land. To accommodate in this habitat, plants have developed critically two modes of surviving desiccating conditions. One via the avoidance of desiccation i.e., common in modern terrestrial vascular plants and has been accomplished by the development of internal water conductance and characters such as highly organized cuticles and effective stomatal mechanism. Meanwhile, some land plants relied on the radical mechanism of survival from desiccation: by desiccation tolerance (DT) i.e., those that which can lose from their vegetative structures all internal water and enter into, and recover from, anhydrobiosis, the cessation of metabolic activity as a result of low intracellular water content (Bewley, 1979). An environment that brings a plant to an air-dried anhydrobiotic state is sufficiently lethal to kill all modern agricultural crops and $>99 \%$ of all vascular land (Alpert, 2000; Alpert and Oliver, 2002). The DT in vascular plants is rare phenomenon. But many of the characters that facilitated desiccation tolerance in ancestral land plants are still commonly found in algae and bryophytes (Alpert, 2005; Oliver et al., 2000). Reports point out that some bryophytes recover from over 20 years of desiccation in herbaria (Alpert, 2000; Stark et al., 2005).

Desiccation tolerance can exist in some phase but be completely absent in another part of an organism's life cycle. The gametophytes of some bryophytes exhibit high degree of tolerance than sporophytes. Desiccation tolerance requires the complex and organized shut-down of metabolism and the occurrence of DT in many distantly related lineages and life stages indicates that there may be significant variation in the mechanisms behind this phenomenon (Alpert and Oliver, 2002).

DT of spores and seeds is well known in vascular plants, but much less is known about vegetative DT in lineages with two separate freeliving stages. Ferns exhibit two separate free-living generations which alternate between independent gametophyte and sporophyte generations. The gametophyte is the site of fertilization, is relatively small, lacks vascular tissue, and either completely lacks or has a poorly developed cuticle. The sporophyte, the primary stage for dispersal, has a well-developed vascular system and a waxy cuticle complete with stomata. These differences alone 
result in unique life-cycle-mediated ecological strategies, especially as they relate to water relations and demography (Watkins et al., 2007).

Because of the well-known resurrection fern like Selaginella sp, the presence of DT in the vascular sporophytes of ferns has been reported to be more common than in other vascular plants. Proctor and Pence (2002) recorded that 64 species of ferns exhibited DT and estimated that less than $1 \%$ of all ferns possess such ability.

\section{MECHANISMS}

\subsection{Water transport}

Ontogenetically, fern fronds are megaphylls arising from rhizome, although in tree ferns the fronds emerge from an apical region of trunk comprised of pith parenchyma, fibers and adventitious roots. Fern vascular tissue is meristeles that are surrounded by an endodermis ; although vessels have been reported in Pteridium aquilinum and members of Astrolepis, Marsilea, and Woodsia (Pittermann et al., 2011), the majority of ferns transport water by means of primitive tracheids the walls of which are perforated by reticulate, homogenous pit membranes. The organization of the vascular bundles within the stipe is highly variable, ranging from the solitary vascular central bundle i.e., haplostele to the multiple bundles - dictyosteles of some species. Fern dictyosteles are most commonly reticulate. In contrast to the typically short and narrow conifer tracheids, which evolved to transport water as well as support the canopy, fern xylem evolved solely for the movement of water leaving support to an outer ring of schlerenchyma fibers (Pittermann et al., 2011; Watkins et al., 2010). Similarly, the length and diameter of fern tracheids varies greatly with conduits in excess of $4 \mathrm{~cm}$ observed in scrambling and weedy species (Pittermann et al., 2011). The ability of fern xylem to explore a broader morph space within the constraints imposed by unicellular conduits probably shaped the competitive ability and persistence of the modern pteridoflora, and may have factored into the evolution of pseudo-woody vascular strategies characteristic of extinct Carboniferous fern taxa (Wilson and Knoll, 2010). That said, the absence of a bifacial vascular cambium and its derivative secondary xylem has led to a developmental scheme that limits not only the hydraulic capacity of pteridophytes, but also branching and the overall architecture of the fern canopy.

\subsection{Free radicals and reactive oxygen species (ROSs)}

Free radicals are atoms or molecules with an unpaired electron, which is readily donated and are highly reactive. Oxygen is a highly oxidizing molecule and readily forms radicals such as singlet oxygen $\left({ }_{1} \mathrm{O}^{2}\right)$, superoxide $\left(\mathrm{O}_{2}{ }^{\bullet}\right)$, the hydroxyl radical $(\bullet \mathrm{OH})$ and nitric oxide (NO•). These are known as reactive oxygen species (ROS) (Halliwell and Gutteridge 1999). ROS cause damage to all macromolecules and subcellular components (Vicre et al., 2004; Berjak, 2006) and being the most damaging consequence of desiccation stress. Because of their highly reactive nature, the accumulation of the products of ROSassociated damage together with the up-regulation of antioxidants to quench ROS activity is normally assayed. However, there is also recent convincing evidence for a role for ROS in intracellular signalling (Bailly, 2004; Laloi et al., 2004). While we have little information on how ROS might play a role in signalling associated with desiccation tolerance, resurrection plants appear to go to great lengths to minimize ROS formation and to quench their activity. It is also evident that the ability to maintain antioxidant potential in the dry state is essential for recovery upon rehydration. For example, Illing et al. (2005) and Farrant (2007) have shown that antioxidant enzymes remain undenatured during desiccation, so that the same enzymes can function to prevent ROS damage during rehydration. In all plants, ROS form as a natural consequence of metabolic processes involving electron transport and thus mitochondria and chloroplasts are major sites of ROS production. Under hydrated conditions, their activity is neutralized and homeostatic control realized by what has been referred to as the "classical" (Kranner and Birtić, 2005) antioxidants such as the water-soluble glutathione ( $\gamma$-glutamylcysteinylglycine; GSH) and ascorbic acid (Asc) (Noctor and Foyer, 1998), the lipid soluble tocopherols and $\beta$-carotene (Munne-Bosch and Alegre 2002) together with enzymes such as superoxide dismutase (SOD), ascorbate peroxidase (APX), other peroxidases, mono- and dehydroascorbate reductases, glutathione reductase (GR) and catalase (CAT). However, under severe water stress conditions, disruption of electron transport results in excess ROS production. While ROS accrue mainly from respiratory metabolism in seeds, there is an additional critical contribution from disruption of photosynthesis in vegetative tissues. Excess energy from excited chlorophyll molecules rapidly results in formation of ROS (Smirnoff, 1993) which are inadequately dealt with by desiccation-sensitive plants, ultimately causing loss of viability. The total antioxidant potential, the 
extent of up-regulation of antioxidant enzymes together with the potential polyphenol antioxidant capacity and anthocyanin protection of the homoiochlorophyllous species is greater than that of the poikilochlorophyllous species. This supports the contention that homoiochlorophyllous resurrection plants might require greater protection against ROS than the poikilochlorophyllous plants, since the latter better avoid ROS formation due to their dismantling the photosynthetic apparatus (Farrant, 2000; Farrant et al., 2003).

Dicranopteris linearis (Burm.F.) Underw. is a desiccation-tolerant forked fern that can tolerate drought. Studies regarding the desiccation rehydration stress in the fern revealed remarkable level of phenolic compound deposits in the tissues. (Kavitha and Murugan, 2016a).Fractionation of phenols by RP-HPLC reveals the waxing and waning pattern of phenolic acids such as ferulic acid, hydroxy benzoic acid and phloroglucinol. The total phenolic content, and phenolic acid profile suggest the protective role of polyphenolics against environmental stress. It seems to act as barrier in the species against desiccation.

Desiccation and rehydration induced greater accumulation of ROS like hydrogen peroxide $\left(\mathrm{H}_{2} \mathrm{O}_{2}\right)$ and superoxide radical $\left(\mathrm{O}_{2}{ }^{-}\right)$in D.linearis (Kavitha and Murugan, 2016b). The active accumulation of these reactive oxygen species (ROS) indicates the severe oxidative stress felt by the fern during desiccation stress. The activity of peroxidases (POX) enzyme (both cytosolic and cell wall bound) examined in the fern revealed that the activity of cytosolic peroxidase was significantly higher throughout the periods of desiccation compared to wall bounded POX. The role of scavenging potential of this enzyme against ROS generated during stress has been established (Kavitha and Murugan, 2016c).

The initial response to ROS production is at the level of plasma membrane. Lipid peroxidation disrupts the membrane integrity of the plant cell. Activation of peroxidation of lipids is one of the earliest response of plants against stress particularly drought stress. $\mathrm{H}+$ adenosine triphosphatases $\mathrm{CH}+$ ATPases) located on the plasma membrane is largely affected by the changes in the membrane lipids.These pumps establish an $\mathrm{H}+$ electrochemical potential across their respective membranes, which can be used as the driving force for secondary active transport. These enzymes maintain homeostasis inside the cell and thus help the cell to compact stress (Małgorzata Janicka-Russak, 2011).The changes in the lipid peroxidation rate studied in D.linearis indicates the presence of an effective anti- oxidative mechanism operating in the plant. Plasma membrane bound $\mathrm{H}+\mathrm{ATPase}$ is a tightly bound integral membrane protein which helps to generate electro chemical proton gradient across the membrane. Thus, this enzyme play critical role in several physiological processes inside the plant and more over it help to resist stress under extreme environmental conditions. Desiccation rehydration stress in D.linearis showed a regulation in $\mathrm{H}+\mathrm{ATPa}$ (Pe activity due to abrupt changes in the lipid peroxidation rate related with stress. Prolonged desiccation in D.linearis resulted in almost a constant H+ATPase activity at par with the control indicating the normal functioning of the plasma membrane even in the stressful conditions. (Kavitha and Murugan, 2016b).

\subsection{Denaturation and sub-cellular perturbations}

As water is progressively lost, the cytoplasm becomes increasingly viscous. Moreover loss of water promotes protein denaturation and membrane fusion, processes that start to occur at water contents of below $50 \%$ RWC or $0.3 \mathrm{~g}^{-g^{-1}}$ (loss of type III and some of type II water) (Walters, 1998). Upon further water loss to $10 \% \mathrm{RWC}, \leq 0.1$ g.g-1 (loss of type II and some type I water) the hydrophobic effect of water that is essential in the maintenance of macromolecular and membrane structure is lost and irreversible sub-cellular denaturation occurs. It is generally thought that desiccation-tolerant systems substitute water with hydrophilic molecules that form hydrogen bonds to stabilize macromolecular interactions in their native configuration (Crowe et al., 1998). In addition to this water replacement, further stabilization of the subcellular milieu is thought to be brought about by vitrification of the cytoplasm by the same water replacement molecules (Hoekstra et al., 2001). Typical water replacement molecules include sugars, particularly sucrose together with oligosaccharides (Berjak, 2006), hydrophilic proteins, particularly late embryogenesis abundant (LEA) proteins (Mtwisha et al., 2006) and small heat shock proteins (Mtwisha et al., 2006) and compatible solutes, including amino acids such as proline (Gaff and McGregor, 1979) and amphiphiles (Hoekstra et al., 2001). Kavitha and Murugan (2016d) previously reported that the FTIR spectroscopic study of the fern D.linearis under desiccation rehydration stress revealed the sensitivity of the carbohydrate metabolism in the fern leaves. In the desiccated fern the band strength was altered suggesting the change of carbohydrate from one form to another i.e., monomeric forms were converted in to sucrose or dimers. After ten days of stress, decrease in band area and band strength indicated decrease in carbohydrate 
synthesis along with conversion of monomers to disaccharides like sucrose/trehalose which act as osmolytes. The increased concentration of reducing sugars in the fern leaves as revealed by the present biochemical analysis suggest the accumulation of sucrose which act as osmolyte. It has been observed that in D.linearis the biosynthesis of proline is activated under dehydration whereas rehydration induces the opposite pathway.

But till now exhaustive metabolomic studies on the various resurrection plants and the role of sugars, sucrose in particular, in subcellular protection against desiccation is not fully elucidated. Sucrose is apparently accumulated in the leaves and roots of all angiosperm resurrection plants examined to date (Whittaker et al., 2004; Peters et al., 2007). Oligosaccharides also accumulate in resurrection plants during drying, but always to a lesser extent than that of sucrose. Sucrose accumulation and trehalose are water replacement molecule add boon to desiccation.

Studies in primitive vascular resurrection plant, Selaginella tamariscina revealed dynamic expression changes of the desiccation-responsive proteins suggesting the plant has developed a specific desiccation tolerant mechanism (Wang et al., 2010). Similarly desiccation rehydration treatment in the fern Polypodium virginianum, showed transient expression of polypeptides necessary during the early stages of rehydration when the rapid initiation of physiological and repair processes are essential (Reynolds and Bewley., 1993). According to Daniel and Gaff (1979), changes in the soluble protein composition were found in all desiccation tolerant and sensitive species of angiosperms after dehydration, but there was no consistent pattern of compositional change within either type of plant. In vivo changes in protein synthesis in desiccation sensitive and tolerant species of grass Sporobolus showed an increase in the protein content of the desiccation tolerant species which is due to increase in the activity of enzymes involved in the tolerant mechanism of the plant( Ghasempour and Kianian., 2007).

Thakur and Bhatla, (2015) employed proteomic approach to analyze sunflower seed development stage revealed specific qualitative expressions of diverse classes of desiccation tolerant low mass proteins, has put forward new information which can be explained further to investigate their respective physiological relevance. Chakrabortee et al., (2007) characterized polypeptides - the late embryogenesis abundant (LEA) proteins as marker for desiccation tolerance.
In beet plants, Gzik (1996) observed that increased levels of amino acids were related to osmotic adjustment for stabilization of water state in tissues under water deficit conditions. In the resurrection plant Barbacenia purpurea the increase of hydroxyproline, serine, valine, histidine, and tyrosine can be an indicative of deposition of extensins in cell wall which provide stability to the cell wall. Moreover, the increase in tryptophan and decrease in shikimic acid observed in B. purpurea suggest a change in metabolism toward the secondary metabolite production, which develops an important role on desiccation tolerance (Suguiyama et al., 2014). In D.linearis increase in serine, valine, tyrosine observed are corroborating with the above results. Up regulation of phenyl alanine indicates the activation of secondary metabolite synthetic pathway. Accumulation of amino acids can be also associated to storage of available substrate for protein synthesis and quick recovery of the plant metabolism after rehydration. In a more recent study using the resurrection lycophyte $S$. lepidophylla, more than half of the amino acids were more abundant in the dry as compared to the hydrated state (Wone et al., 2013).

\section{CONCLUSION AND FUTURE OUTLOOK}

There is good reason to suspect that physiological and morphological traits in the ferns are in a coordinated manner that was consistent with the Cenozoic diversification of the fern epiphytic flora, and possibly other fern radiations across the post-Eocene landscape. Future research will seek to elucidate the structure-function tradeoffs associated with variable stealer structure and pit membrane traits with respect to hydraulic function and cavitation resistance, since so little is known about the functional value of the myriad of bundle arrangements characteristic of fern taxa. Since the fern vascular system is anatomically tractable, future work will explore the relationships between stele arrangements, frond venation and gas-exchange, with the goal of placing the results in a broad phylogenetic context. Working toward a concurrent understanding of how gametophyte physiology parallels adaptive traits in the sporophyte will be critical toward building a comprehensive picture of fern radiations since gametophyte establishment may push the physiological and niche boundaries of their associated sporophytes.

Due to their seedless, treeless habit and a lifestyle seemingly resigned to the shady forest understory, pteridophyte physiology has long lingered in the shadow of conifers and angiosperms. However, literature survey has shown ferns to 
physiologically competitive, resistant to stress, highly diverse and extremely adaptive, so it is time for this ancestral lineage to step into the spotlight of evolutionary eco-physiology. Indeed, the understanding of the evolution of plant water transport would be incomplete without a vigorous examination of the physiological traits that contributed to the 400 million year-long success of these persistent plants. With the advent of more transcriptome, proteome and metabolome studies, these similarities will probably become increasingly apparent.

\section{REFERENCES}

Alpert, P. and M.J. Oliver, (2002). Drying without dying. In: Black $M$, Pritchard HW, eds. Desiccation and survival in plants. Wallingford, UK: CABI Publishing, 3-43.

Alpert, P., (2000). The discovery, scope, and puzzle of desiccation tolerance in plants. Pl. Ecol. 151: 517.

Alpert, P., (2005). The limits and frontiers of desiccation-tolerant life. Int. Comp. Biol. 45: 685-695.

Andrea Bennici, (2008). Origin and early evolution of land plants. Comm. Int. Biol. 1:2, 212-218.

Bailly, C., (2004). Active oxygen species and antioxidants in seed biology. Seed Sci. Res. 14: 93-107.

Berjak, P. (2006). Unifying perspectives of some mechanism basic to desiccation tolerance across life forms. Seed Sci. Res. 16: 1-15.

Bewley, J.D. (1979). Physiological-aspects of desiccation tolerance. Ann. Rev. Pl. Physiol. Pl. Mol. Biol. 30: 195-238.

Chakrabortee, S., C. Boschetti, L.J. Walton, S. Sarkar, D.C. Rubinsztein and A. Tunnacliffe, (2007). Hydrophilic protein associated with desiccation tolerance exhibits broad protein stabilization function, PNAS, 13(104) 46: 18073-18078.

Crowe, J.H., J.F. Carpenter and L.M. Crowe, (1998). The role of vitrification in anhydrobiosis. Ann. Rev. Physiol. 60: 73-103.

Daniel, V. and D.F. Gaff, (1980). Dessication-induced Changes in the Protein Complement of Soluble Extracts from Leaves of Resurrection Plants and Related Desiccation-sensitive Species. Ann. Bot. 45(2): 173-181.

Farrant, J.M., (2000). A comparison of mechanisms of desiccation tolerance among three angiosperm resurrection plant species. Pl. Ecol. 151: 29-39.

Farrant, J.M., (2007). Mechanisms of desiccation tolerance in Angiosperm resurrection plants. In: Jenks MA, Wood AJ (Eds) Plant Desiccation Tolerance, CABI Press, Wallingford.
Farrant, J.M., C. Vander Willigen, D.A. Loffell, S. Bartsch and A. Whittaker, (2003). An investigation into the role of light during desiccation of three angiosperm resurrection plants. Pl. Cell Environ. 26: 1275-1286.

Gaff, D.F., and G.R. McGregor, (1979). The effect of dehydration and rehydration in the nitrogen content of various fractions from resurrection plants. Biol. Plantarum 21: 92-99.

Ghasempour, H.R. and J. Kianian, (2007). The Study of Desiccation-Tolerance in Drying Leaves of the Desiccation-Tolerant Grass Sporobolus elongatus and the Desiccation-Sensitive Grass Sporobolus pyramidalis. Pak. J. Biol. Sci. 10: 797801.

Gzik, A. (1996). Accumulation of proline and pattern of $\alpha$-amino acids in sugar beet plant in response to osmotic, water and salt stress. Environ. Exper. Bot. 36: 29-38.

Halliwell, B. and J.M.C. Gutteridge, (1999). Free Radicals in Biology and Medicine (3rd Edn), Oxford University Press, Oxford, 936 pp.

Hoekstra, F.A., E.A. Golovian and J. Buitink (2001). Mechanisms of plant desiccation tolerance. Trends in Pl. Sci. 6: 431-438.

Illing, N., K. Denby, H. Collett, A. Shen and J.M. Farrant, (2005). The signature of seeds in resurrection plants: a molecular and physiological comparison of desiccation tolerance in seeds and vegetative tissues. Int. Comp. Biol. 45: 771-787.

Kavitha, C.H. and K. Murugan, (2016a). Phenolic Compounds as Stress Markers in the Fern Dicranopteris linearis (Burm.F.) Underw.: A Search. J. Phytochem. Photon, 117: 378-385.

Kavitha, C.H. and K. Murugan, (2016b). Desiccationinduced changes in lipid peroxidation superoxide level and cell membrane H+ATP ase activity in forked fern -Dicranopteris linearis (Burm.f.) Underw. Int. J. Adv. Res. 3: 588-593.

Kavitha, C.H. and K. Murugan, (2016c). Dissimilitude response of peroxidases of Dicranopteris linearis(Burm.f.)Underw. against desiccation and rehydration stress. IOSR J. Biotechnol. Biochem. (IOSR-JBB) 2: 36-41.

Kavitha, C.H. and K. Murugan, (2016d). Fourier Transform Infrared Fingerprint of Desiccated Fronds of Forked Fern- Dicranopteris linearis (Burm.f.) Underw. : Some Observations. Phytomorphol. 66(1and2):13-19.

Kranner, I. and S. Birtić, (2005). A modulating role for antioxidants in desiccation tolerance. Int. Comp. Biol. 45: 734-740. 
Laloi, C., K. Apel and A. Danon, (2004). Reactive oxygen signaling: the latest news. Curr. Opin. Pl. Biol. 7: 323-328.

Małgorzata Janicka-Russak, (2011). Plant Plasma Membrane H+-ATPase in Adaptation of Plants to Abiotic Stresses, Abiotic Stress Response in Plants - Physiological, Biochemical and Genetic Perspectives, In Tech.

Mtwisha, L., J. Farrant, W. Brandt and G.G. Lindsey, (2006). Protection mechanisms against water deficit stress: Desiccation tolerance in seeds as a study case. In: Ribaut J (Ed) Drought Adaptation in Cereals, Haworth Press, New York, pp 531549.

Munné-Bosch, S. and L. Alegre, (2000). Plant aging increases oxidative stress in chloroplasts. 214(4):608-15.

Noctor, G. and C.H. Foyer, (1998). Ascorbate and glutathione: keeping active oxygen under control. Ann. Rev. Pl. Physiol. Pl. Mol. Biol. 49: 249-279.

Oliver, M.J., Z. Tuba and B.D. Mishler, (2000). The evolution of vegetative desiccation tolerance in land plants. Pl. Ecol. 151: 85-100.

Peters, S., S.G. Mundree, J.A. Thomson, J.M. Farrant and F. Keller, (2007). Protection mechanisms in the resurrection plant Xerophyta viscosa (Baker): both sucrose and raffinose family oligosacharides (RFOs) accumulate in leaves in response to water deficit. J. Experimental Bot.

Pittermann, J., E. Limm, C. Rico and M. Christman, (2011). Structure function constraints of tracheid-based xylem: a comparison of conifers and ferns. New Phytologist, 192: 449-461.

Proctor, M.C.F. and V. Pence, (2002). Vegetative tissues: bryophytes, vascular resurrection plants and vegative propagules. In: Black $\mathrm{M}$, Prichard HW,eds. Desiccation and survival in plants: drying without dying. Wallingford,UK: CAB International, 207-237.

Reynolds, T.L. and J.D. Bewley, (1993). Characterization of protein synthetic changes in a desiccation-tolerant fern, Polypodium virginianum. Comparison of the effects of drying, rehydration and abscisic acid. J. Experimental Bot. 44: 921-928.

Smirnoff, N., (1993). The role of active oxygen in the response of plants to water deficit and desiccation. New Phytologist, 125: 214-237.

Stark, L.R., L. Nichols, D.N. McLetchie and M.L. Bonine, (2005). Do the sexes of the desert moss Syntrichia caninervis differ in desiccation tolerance? A leaf regeneration assay. Int. J. Pl. Sci. 166: 21-29.
Suguiyama, V.F., E.A. Silva, S.T. Meirelles, D.C. Centeno and M.R. Braga, (2014). Leaf metabolite profile of the Brazilian resurrection plant Barbacenia purpurea Hook. (Velloziaceae) shows two time-dependent responses during desiccation and recovering. Frontiers Pl. Sci. 5(96): 1-13.

Thakur, A. and S.C. Bhatla, (2015). Proteomic analysis of oil body membrane proteins accompanying the onset of desiccation phase during sunflower seed development. J. Pl. Signal. Behav. 10: 12: 1-13.

Vicre, M., J.M. Farrant and A. Driouich, (2004a). Insights into the mechanisms of desiccation tolerance among resurrection plants. Pl. Cell Env. 27: 1329-1340.

Walters, C. (1998). Understanding the mechanisms and kinetics of seed ageing. Seed Sci. Res. 7: 223244.

Watkins, J.E. Jr., M.C. Mack and S.S. Mulkey, (2007). Gametophyte ecology and demography of epiphytic and terrestrial tropical ferns. Am. J. Bot. 94: 701-708.

Watkins, J.E., N.M. Holbrook and M.A. Zwieniecki, (2010). Hydraulic properties of fern sporophytes: consequences for ecological and evolutionary diversification. Am. J. Bot. 97: 2007-2019.

Whittaker, A., T. Martinelli, A. Bochicchio, C. Vazzana and J. Farrant, (2004). Comparison of sucrose metabolism during the rehydration of desiccation-tolerant and desiccation-sensitive leaf material of Sporobolus stapfianus. Physiologia Plantarum, 122: 11-20.

Wilson, J.P. and A.H. Knoll, (2010). A physiologically explicit morpho space for tracheid-based water transport in modern and extinct seed plants. Paleobiology, 36: 335-355.

Wone, B.W.M., A. Yobi, W. Xu, D.C. Alexander and L. Guo, (2013). Metabolomic Profiling in Selaginella lepidophylla at Various Hydration States Provides New Insights into the Mechanistic Basis of Desiccation Tolerance. Molecul. Pl. 6: 369-385.

Xiaonan Wang, Sixue Chen, Heng Zhang, Lei Shi, Fenglin Cao Lihai Guo, Yongming Xie, Tai Wang, Xiufeng Yan and Shaojun Dai, (2010). Desiccation Tolerance Mechanism in Resurrection Fern-Ally Selaginella tamariscina revealed by Physiological and Proteomic Analysis, J. Proteome Res. 9(12), 6561-6577. 